\title{
The Relationship Between Work-Disability Duration and Claimant's Expected Time to Return to Work as Recorded by Workers' Compensation Claims Managers
}

\author{
Amanda E. Young ${ }^{1} \cdot$ Elyssa Besen $^{1} \cdot$ Joanna Willetts $^{1}$
}

Published online: 26 July 2016

(c) The Author(s) 2016. This article is published with open access at Springerlink.com

\begin{abstract}
Purpose This research sought to determine whether there is a relationship between claimants' expected time to return to work (RTW) as recorded by claims managers and compensated days of work disability. Methods We utilized workers' compensation data from a large, United States-based insurance company. RTW expectations were collected within 30 days of the claim being reported and these were compared with the termination of total temporary indemnity payments. Bivariate and hierarchical regression analyses were conducted. Results A significant relationship between expected time to RTW and compensated disability duration was observed. The unadjusted correlation between work-disability duration and expected time to RTW was $.25(p<.001)$. Our multivariate model explained $29.8 \%$ of the variance, with expected time to RTW explaining an additional $9.5 \%$ of the variance in work-disability duration beyond what was explained by the covariates. Conclusion The current study's findings support the hypothesis that claimant RTW estimates as recorded by claims managers are significantly related to compensated-disability duration, and the relationship is maintained after controlling for variance that can be explained by other variables available within workers' compensation databases.
\end{abstract}

Keywords Recovery expectations · Disability management · Work-disability prevention · Workers' compensation · Return-to-work · Prognostic factors

Amanda E. Young

amandae.young@libertymutual.com

1 Center for Disability Research, Liberty Mutual Research Institute for Safety, 71 Frankland Road, Hopkinton, MA 01748, USA

\section{Introduction}

With an increasing number of studies finding that a worker's medical condition incompletely explains return to work (RTW) following occupational injury, the role of psychosocial influences has come into question $[1,2]$. Of the psychosocial variables that have been examined, "RTW expectation" has frequently been found to relate to outcomes [3, 4]. Questions are now being raised regarding whether a worker's expectations for RTW can be used in a clinical setting to gain an understanding of likely future outcome.

The relationship between RTW expectations and RTW outcomes has been observed not only in numerous geographical and social settings, but also across a variety of health conditions, disability durations, and methods of scientific inquiry [5]. However, while study results have indicated a relationship between expectations and RTW, our understanding of the relationship is still limited. The reasons for this are numerous, with some of the most important being: inconsistency in findings, study sample sizes that have limited the inclusion of covariates, and data being collected by researchers rather than those involved in the claims process.

Regarding inconsistency of findings, research has indicated that a claimant's self-assessment may be more or less accurate depending on their condition. For example, in their analysis of 1040 workers' compensation claimants, Gross and Battié found that recovery expectations predicted recovery in workers filing injury claims for back pain, but not other musculoskeletal conditions including sprains, strains, or pain of other body parts besides the back, other injuries such as fracture, dislocation, or amputation, nor other compensable conditions such as carpal tunnel [6]. 
Regarding sample size, studies have tended to have sample sizes that have restricted their analytical options and the number of covariates that could be included. Of the studies that have investigated the relationship between expectations and RTW outcomes, the maximum sample size was 1566 [7]. This study was conducted in Canada and found that four measures of recovery explained one-sixth of the variation in time receiving benefit. While expectations regarding RTW were not found to be individually predictive of time receiving benefits, this is likely due to the question about whether or not the respondent thought they would recover enough to return to their usual job. The next largest sample comprised 1068 people with a workers' compensation claim for back pain in Washington State [8]. In this study, they found that very low recovery expectations (operationalized as being very uncertain about whether or not they would be working in 6 months' time) were significant independent predictors of chronic work disability. Four other studies have had samples sizes of approaching 1000 [6, 9-11]. In the majority of the remainder of studies, sample size has tended to be around 500 [e.g., 12-17].

Regarding the impact of those collecting the data, to date, data has mainly been collected by research staff. It is possible that claimant responses are influenced by who is asking the question. For example, workers may be more willing to give an honest response to an un-invested party. Or, they may give what they believe to be a socially desirable (biased) response to someone with an interest in their specific case. While there are some studies in which those collecting the data have been directly involved in the RTW process [e.g., 18-20] in these cases data has been collected by a treating health care professional: in the study by Waylett-Rendall and Niemeyer [20], data were collected at the point of care by therapists working in the hand therapy program; in the case of Nieuwenhuijsen et al. [18], data were collected by an occupational physician; and in the study by Gross and Battié [19], data were abstracted from the treating facility's database. As yet, there has been no study of the relationship between RTW expectations data as collected by an insurer representative as part of the case management process and work-disability duration. Given that this stakeholder group is one of the most likely to implement interventions based on the information received, understanding the impact of who is asking is important for both research and clinical reasons.

\section{Aims and Hypotheses}

The research sought to determine whether there is a relationship between claimants' expected time to return to work as recorded by claims managers in the administrative database of a large workers' compensation insurer and compensated days of work disability. We hypothesized that claimant estimates would be related to work-disability durations as calculated using payments for missed work time. In addition, we sought to determine if variance in work-disability duration that is accounted for by claimants' RTW expectations is greater than can be achieved with demographic and injury variables contained within workers' compensation (WC) administrative databases.

\section{Methods}

In the current study, we utilized the WC data from a large, United States-based insurance company. The data covers claims from a variety of organizations with different workforce sizes and from various industries. We focused on data pertaining to claimants aged 18-80 who had at least 7 days of compensated temporary total disability (TTD) and who reported expecting to return to work. The reason for focusing on people with at least 7 days of TTD was that this timeframe represents a substantial period of time away from the workplace. As such, findings are likely to be more applicable to the subset of injured workers that has the potential to benefit most from work-disability prevention initiatives. So as to allow for at least 18 months of claims maturation, data were extracted for persons with an accepted claim that occurred from January 1, 2010 until December 31, 2013.

As part of the insurer's claims management process, claimants who are off work, but not necessarily receiving indemnity payments, were asked about their RTW expectations. For the current study, we restricted our sample to claimants who provided an estimated RTW date within 30 days of the date that their injury was first reported to the workers' compensation insurer. The reason for this is that our focus is on early risk prediction. We also restricted the sample to claims that had just one episode of TTD in the 365 days following RTW expectation data collection. Our justification for this is that while it is likely that the majority of respondents would reference their most immediate RTW when asked about their expectations, we could not be sure of this. Excluding people with multiple episodes of work-disability (TTD) means that we could be confident of the RTW the claimant was referencing. Similarly, in instances where a claimant had multiple claims within our data collection period (2010-2013), all claims for this individual were also excluded so as to avoid confusion about what incident a person was referencing when making RTW expectations.

Consistent with prior studies of disability recurrence, we considered a new episode of TTD to have occurred if there was more than a 7-day gap between TTD payments [21]. If the duration between TTD payments was 7 days or less, it 
was considered a single episode. We also excluded claimants who received a lump sum payment within 365 days of the date that the prediction was made of when a claimant would return to work. The reason for this is that in such cases, the end of TTD payments is a less reliable proxy for RTW. Claimants with missing data were also excluded. After the sample restrictions, 15,277 claims were included in our analyses. Figure 1 illustrates where sample was lost due to the various restrictions.

Three key dates were utilized in this study. These were the date of injury report, the date the RTW estimate was made, and the date that consecutive temporary total disability (TTD) payments ended (note that gaps of 7 days or less were ignored). The date that the injury was reported was used to assess whether an estimate for expected time to RTW was made within 30 days of the injury report day. The date the RTW estimate was made was then used to calculate (1) the expected length of time (days) to RTW and (2) the actual length of time (days) to RTW, estimated using the date that TTD payments ended. The key dates and associated measures are illustrated in Fig. 2.

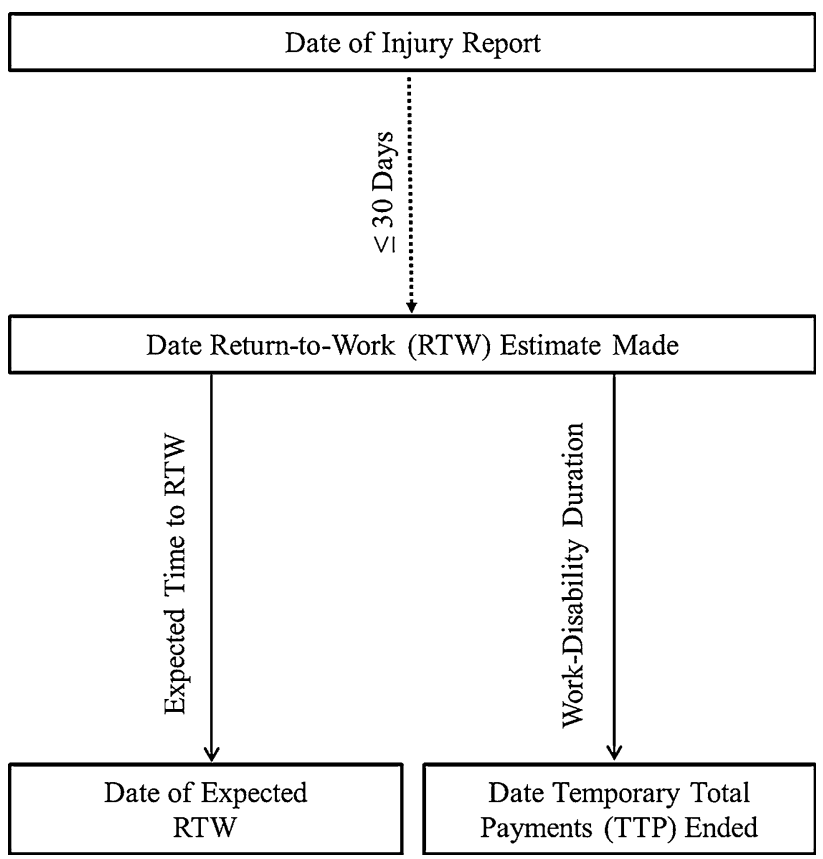

Fig. 2 Time points used to calculate expected time to return to work and work-disability duration
Fig. 1 Flow chart illustrating sample lost due to exclusion criteria

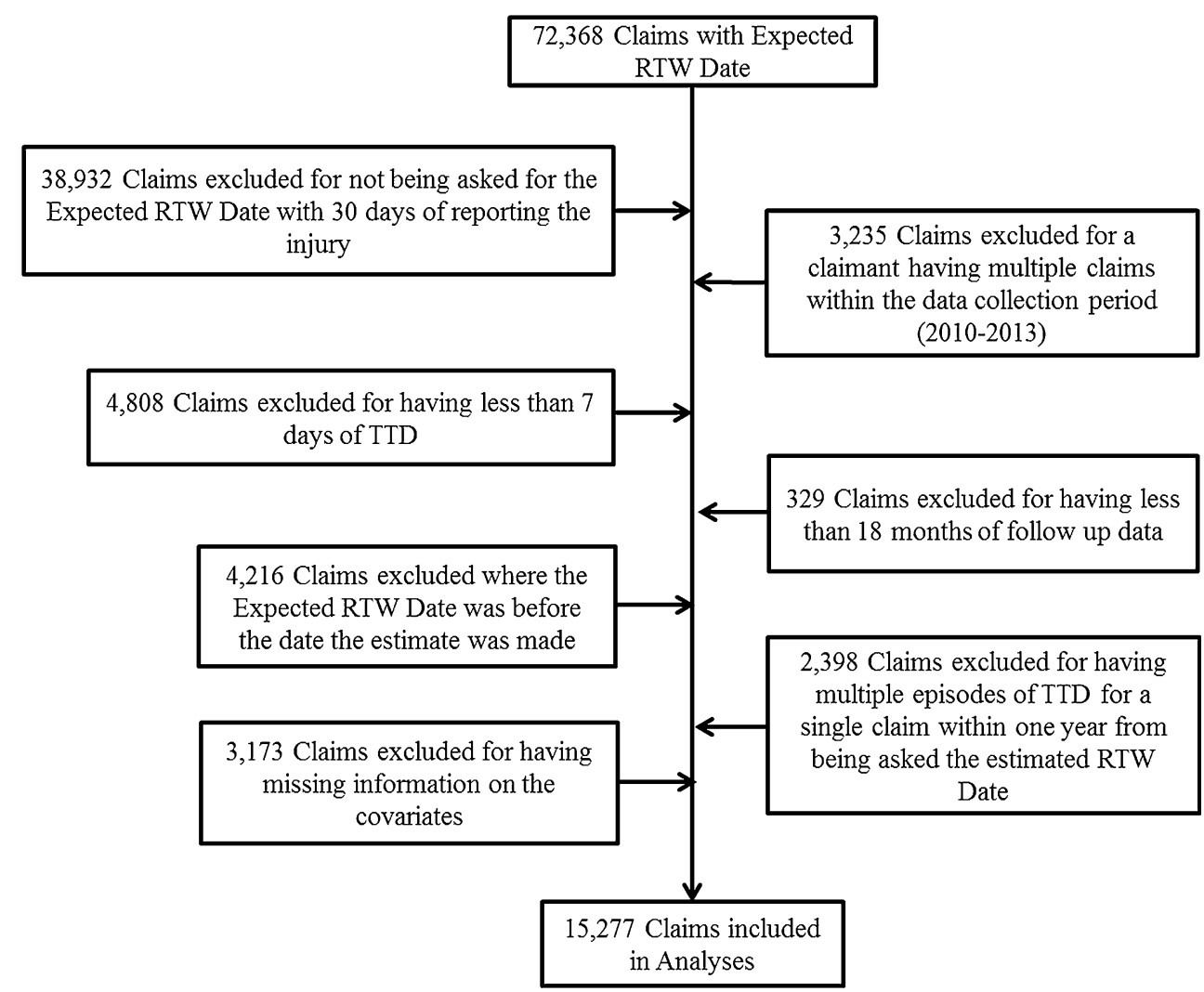




\section{Measures}

\section{Outcome Variable}

Work-disability duration was the outcome variable for our analyses. It was calculated as the number of days from the date at which claimants first made an estimate of when they would RTW until the date at which consecutive TTD payments finished. TTD was considered to have ended when no TTD days were taken for at least a 7-day consecutive period. Ignoring gaps in payment is consistent with prior research [22-25]. We opted to use a relatively conservative ignored-gap period as we felt that extending the period beyond 7 days would result in defining people who had attempted to RTW, but were unable to maintain their rehabilitation gains (i.e. experienced a work-disability recurrence [21]) as experiencing a single episode of work disability. In cases of work-disability recurrence, we would not expect that a claimant's original RTW estimates would relate to the end of a later episode of work disability. Work-disability duration was top coded at 365 days in cases where disability duration exceeded 1 year. This occurred in 1010 claims. In the analyses, the natural log of disability duration was used to address issues with normality.

\section{Predictor Variable}

The main predictor variable for our analyses was the claimant's expected time to RTW. A recent review of research into RTW expectations found much diversity in the way expectations have been assessed [5]. Based on the review, the following measure was offered as a means of advancing the field: (1) "Do you expect to go back to work?", Response options: "yes", "no", "unsure". If "yes" or" unsure": (2) "If you had to estimate your timeframe for going back to work, what would it be? Response options: "Time from today: days/weeks/months (circle one)". While the exact wording used by the claims managers to collect the RTW expectations data is not standardized, the data collected is consistent with what was recommended based on the review [5].

For this study expected time to RTW was calculated for people who responded that they did expect to RTW, or that they were unsure but were able to give an approximate timeframe for doing so. The expected time to RTW was defined as the number of days from the date the claimant was first asked to estimate when he/she would RTW, until the date the claimant reported expecting to RTW. The expected length of time until RTW was top coded at 365 days in cases where the length of time exceeded 1 year. This occurred in 56 claims. The natural $\log$ of the expected length of time until returning to work was used in analyses to address issues with normality.

\section{Covariates}

The following 11 covariates were used: age, tenure, gender, industry, surgery post-RTW expectations collection, comorbidity, perceived pain, prior injury, diagnosis, jurisdiction, and number of days between the report date and the date the RTW expectation was made.

- Age was measured in years based on the claimant's age at the time of injury.

- Tenure was also measured in years based on a claimant's organizational tenure at the time of injury. Tenure was top coded at 25 years (occurred in 643 cases); in analyses, the natural $\log$ of the length of tenure was used to address issues with normality.

- Gender was coded 1 for female and 0 for male.

- Ten industry groupings, which roughly correspond to the U.S. Department of Labor's Standard Industry Classification (SIC) groups [26], were included in the analyses: agriculture, forestry and fishing, construction, finance and insurance, manufacturing, mining, retail trade, services, transportation, public administration, and wholesale trade.

- A surgery indicator was used in analyses to control for claimants receiving surgery after the claimant had made a prediction about the date at which he/she would RTW. This indicator was constructed based on two criteria from reviewing the claimant's medical bills for the first year following the date the injury occurred. First, the claimant needed to have a bill containing at least one Current Procedural Terminology Code (CPT) in the broad category of surgery (ranging from 10,000 to 69,990 ) within the first year following the date at which the RTW estimate was made. Second, the claimant also needed to have a bill containing at least one CPT code in the broad category of Anesthesia (ranging from 00100 to 01999) occurring within 6 days of the CPT surgery code to allow for minor administrative billing inconsistencies. Claimants were coded 1 for having a surgery if both criteria were met and 0 if they did not meet both criteria after making a prediction about the RTW date.

- Comorbidity was coded 1 if the claimant reported having hypertension and/or diabetes and 0 if the claimant had neither condition. These data were collected by the claims manager as self-reported by the claimant.

- Perceived pain level was coded on an eleven-point scale from 0 indicating "no pain" to 10 indicating "lots 
of pain" [27]. These data were collected by the claims manager as self-reported by the claimant.

- Prior injury was categorized into: claimant did not have a prior injury (reference category), claimant had a prior injury related to the current claim, and claimant had a prior injury that was unrelated to the current claim. These data were collected by the claims manager as self-reported by the claimant.

- The primary diagnosis which best captured the reason for the claim (as defined by the claims manager and based on the self-report of the claimant) was assigned using the International Classification of Diseases, ninth revised edition (ICD-9). The diagnoses were collapsed into fourteen different groups (see Table 1 for full listing of diagnosis groups). An analysis was conducted whereby the codes applied by the case manager were compared with medical billing information. In $82.14 \%$ of cases there was at least one bill coded to the diagnosis groupings displayed in Table 1. In $91.62 \%$ of cases there was concordance at the ICD-9 chapter level.

- Jurisdiction was coded based on the state in which the injury occurred.

- The number of days between the injury report date and the date the RTW expectation was made was measured continuously in days.

\section{Analyses}

Given that only a small proportion of cases were top coded for work-disability duration $(6.6 \%)$, hierarchical regression was used to estimate the relationship between claimant's expected time to RTW and work-disability duration, as well as to assess whether RTW expectations account for additional variance in work-disability duration beyond that which could be accounted for by selected covariates contained within the WC insurer's administrative databases. In the first step of the analyses, the covariates, were added to the model predicting work-disability duration. In the second step, the expected time to RTW was added to the model. The change in the amount of variance accounted for $\left(\mathrm{R}^{2}\right)$ in the first model compared to the second model was used to examine the amount of additional variance accounted for by RTW expectations. To test the hypothesis that claimants' estimates for expected RTW are related to actual work-disability duration, the coefficient for the expected time to RTW in the second model was used. All analyses were conducted using STATA 13.1 (College Station, TX). The user-written program "hireg" was utilized to implement the hierarchical regression model [28].

\section{Results}

In total, 15,277 claims were included in the analyses. The mean work-disability duration was 78.7 days (SD 102.8), and the mean expected time to return to work was 33.4 days (SD 42.8). Slightly more than two-thirds $(67.8 \%)$ of the claims were for men. Claimants' ages ranged from 18 to 80 years with an average age of 42.6 years and the average length of tenure was 5.8 years. Approximately a fifth $(21.7 \%)$ of participants reported having a comorbid health condition (having hypertension and/or diabetes). The average perceived pain level was 5.4. The majority of claimants did not have a prior injury $(70.7 \%)$, while $11.1 \%$ of claimants had a prior injury that was related to their current claim and $18.2 \%$ had a prior injury that was not related to their current claim. The average number of days between the report date for the claim and when a claimant made a prediction about the date at which he/ she would RTW was 9.7 days. Additional descriptive statistics can be found in Table 1.

Although the average expected time to RTW was less than the time it took for TTD payments to cease (33 vs. 79 days), analysis revealed a significant relationship between expected time to RTW and work-disability duration. The unadjusted correlation between work-disability duration and the expected time to RTW was .25 $(p<.001)$. To examine how closely work-disability duration aligned with the expected time to RTW, we categorized both variables into eight categories and conducted cross-tabulations among the categories (see Table 2). In line with our expectations, within each of the length-of-disability categories, the largest percentage of claims were in the same or similar number-of-days category for the expected time to RTW. The most accurate group were those who expected to be back at work in 1-7 days, with $43 \%$ of this group making a correct estimation. Approximately $10 \%$ of the sample had an expected time to RTW of 7 days or less and a work-disability duration of 7 days or less. In contrast, less than $1 \%$ of the sample had an expected time to RTW of 181 days or longer and a work-disability duration of 7 days or less. Those who expected to return to work in more than 7 days tended to be less accurate, but in most cases the rate of accuracy was still greater than $20 \%$. The rate of accuracy for those who expected to be off work for more than 7 days was $22 \%$. Overall, $28 \%$ of the sample made estimates that were within 7 days $( \pm)$ of their TTD payments ending; and $41 \%$ were within 14 days $( \pm)$ of when their TTD payments ended.

The adjusted relationship between expected time to RTW and work-disability duration while controlling for selected variables contained within the WC insurer's administrative database was tested using a two-step analytical procedure. In the first step of the analyses, the 


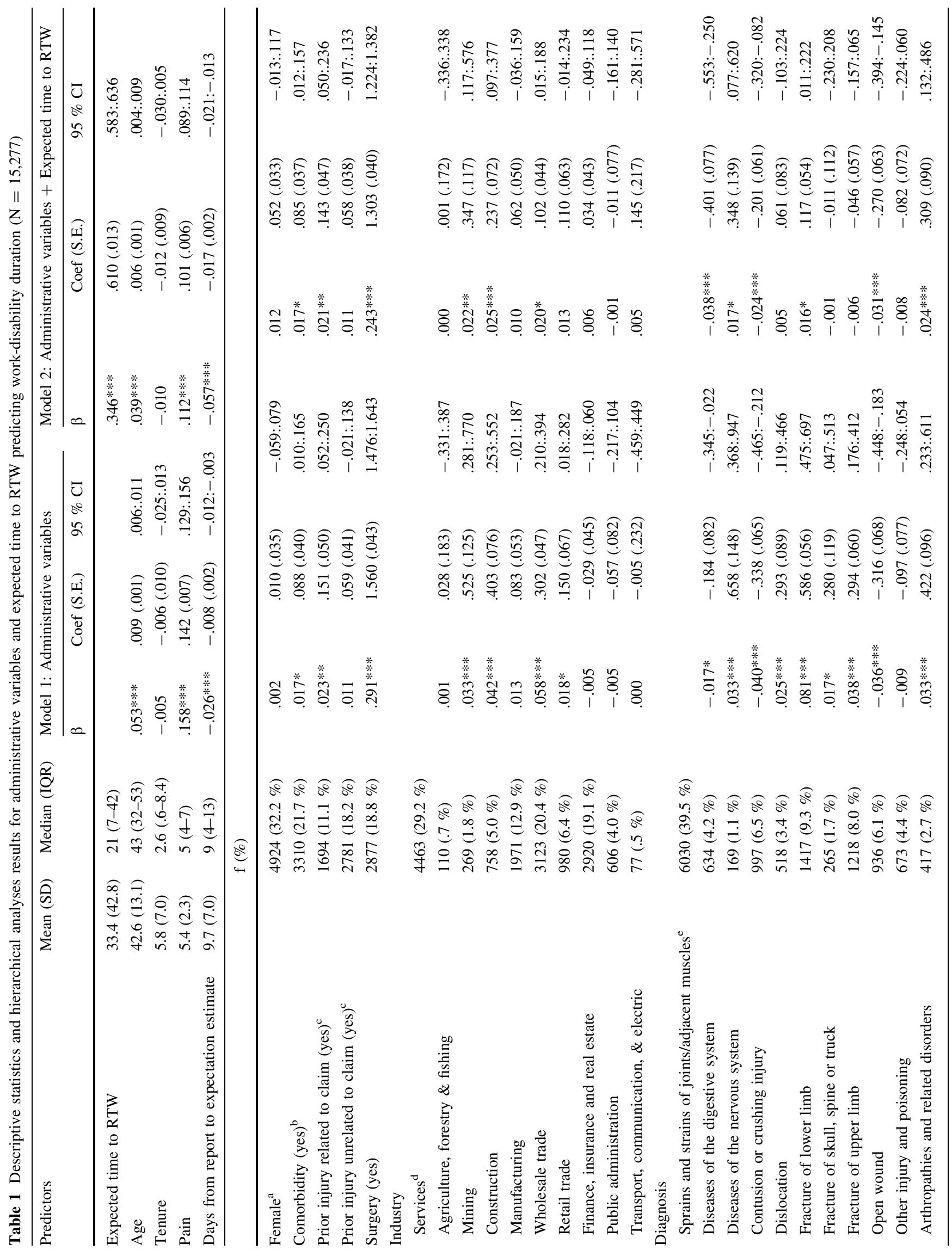




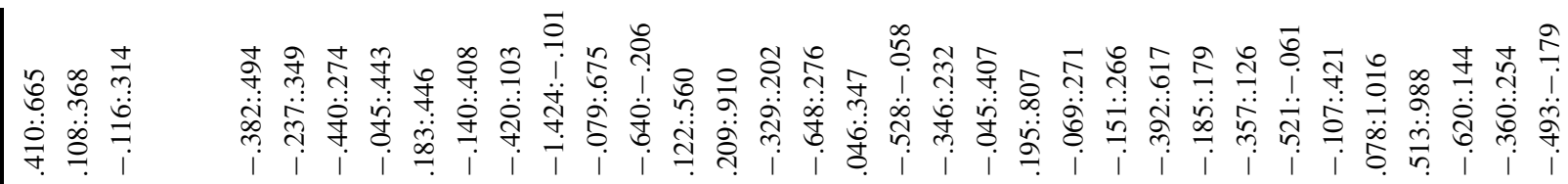

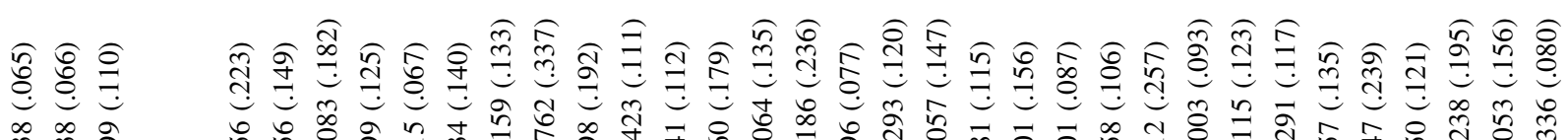

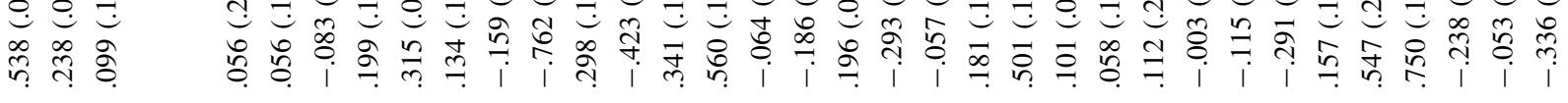

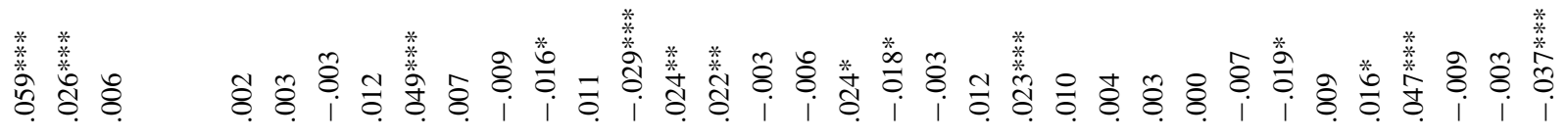

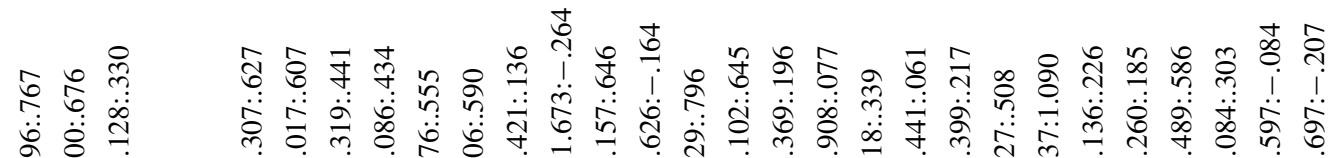

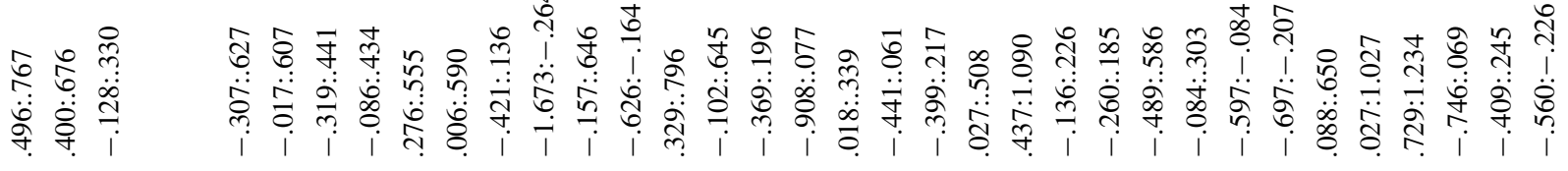

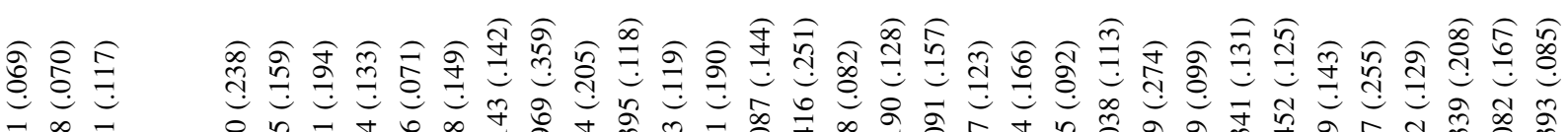
乃.

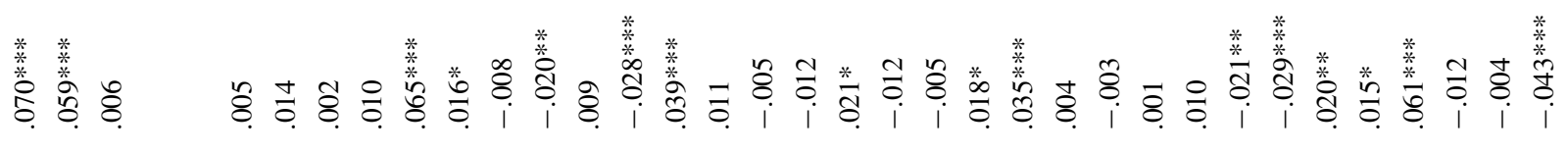

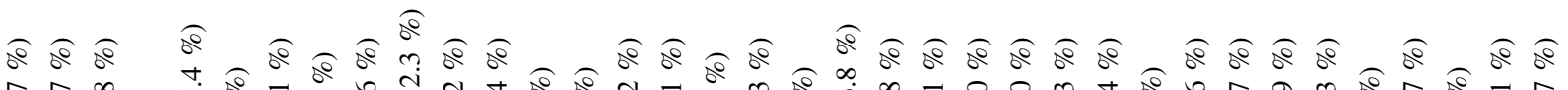

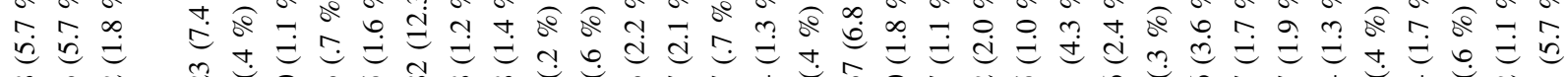

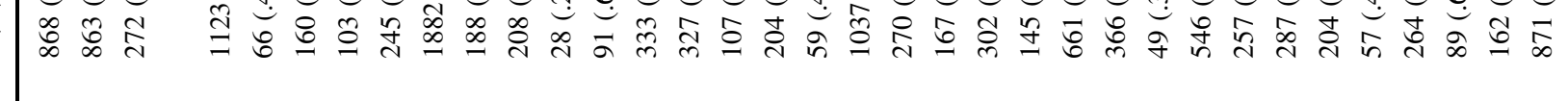




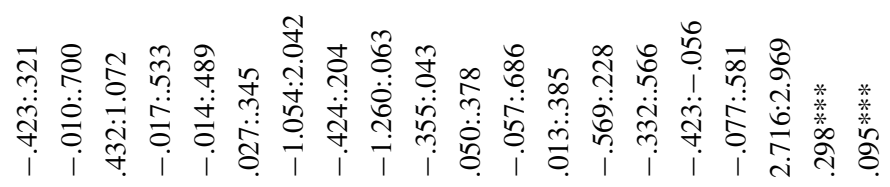

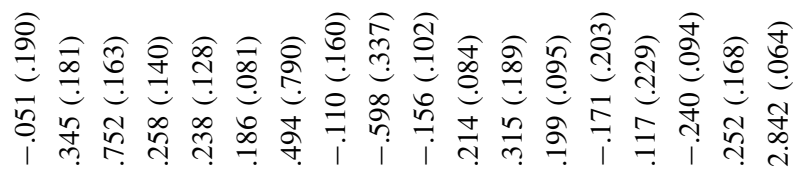

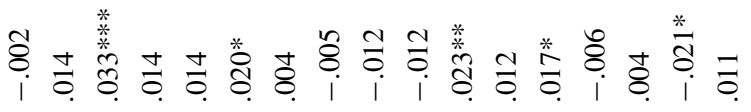

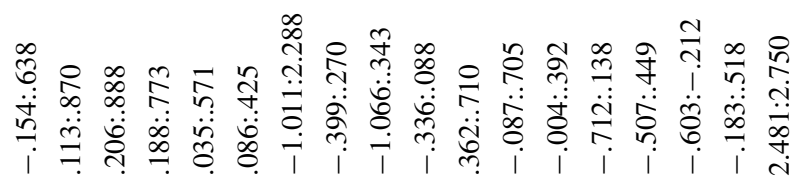

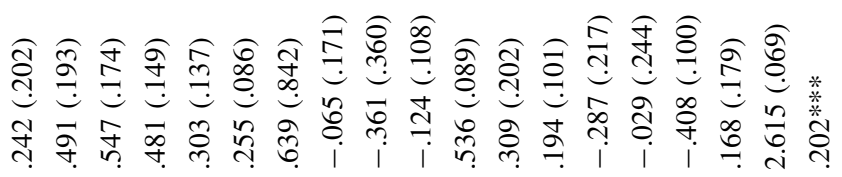

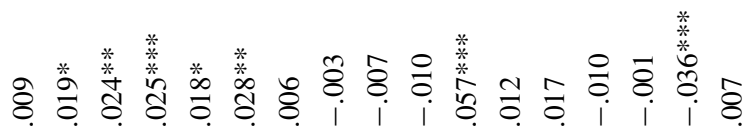


Table 2 Percentage and number of claims in work-disability duration categories by expected time to return to work (RTW) categories

\begin{tabular}{|c|c|c|c|c|c|c|c|c|c|}
\hline \multirow{2}{*}{$\begin{array}{l}\text { Expected time } \\
\text { to RTW (days) }\end{array}$} & \multicolumn{9}{|c|}{ Work-disability duration (days) } \\
\hline & $\begin{array}{l}1-7 \\
(\mathrm{n}=2652)\end{array}$ & $\begin{array}{l}8-14 \\
(n=1776)\end{array}$ & $\begin{array}{l}15-30 \\
(\mathrm{n}=2619)\end{array}$ & $\begin{array}{l}31-60 \\
(\mathrm{n}=2774)\end{array}$ & $\begin{array}{l}61-90 \\
(\mathrm{n}=1542)\end{array}$ & $\begin{array}{l}91-180 \\
(\mathrm{n}=1797)\end{array}$ & $\begin{array}{l}181-365 \\
(\mathrm{n}=1107)\end{array}$ & $\begin{array}{l}>365 \\
(\mathrm{n}=1010)\end{array}$ & $\begin{array}{l}\text { Total } \\
(\mathrm{N}=15,277)\end{array}$ \\
\hline \multirow[t]{2}{*}{$1-7$} & $43.0 \%$ & $14.7 \%$ & $14.7 \%$ & $11.3 \%$ & $4.9 \%$ & $5.1 \%$ & $2.9 \%$ & $3.5 \%$ & $25.1 \%$ \\
\hline & 1650 & 563 & 562 & 433 & 187 & 194 & 112 & 133 & 1650 \\
\hline \multirow[t]{2}{*}{$8-14$} & $14.4 \%$ & $20.9 \%$ & $22.7 \%$ & $17.1 \%$ & $7.9 \%$ & $7.5 \%$ & $4.5 \%$ & $4.9 \%$ & $16.0 \%$ \\
\hline & 351 & 511 & 555 & 418 & 194 & 183 & 111 & 120 & 2443 \\
\hline \multirow[t]{2}{*}{$15-30$} & $10.0 \%$ & $10.5 \%$ & $22.8 \%$ & $20.6 \%$ & $10.1 \%$ & $11.9 \%$ & $7.5 \%$ & $6.6 \%$ & $22.7 \%$ \\
\hline & 348 & 365 & 791 & 715 & 351 & 413 & 261 & 230 & 3474 \\
\hline \multirow[t]{2}{*}{$31-60$} & $6.5 \%$ & $7.6 \%$ & $14.6 \%$ & $24.9 \%$ & $14.5 \%$ & $14.8 \%$ & $9.2 \%$ & $8.0 \%$ & $21.2 \%$ \\
\hline & 210 & 247 & 473 & 805 & 468 & 478 & 299 & 259 & 3239 \\
\hline \multirow[t]{2}{*}{ 61-90 } & $4.8 \%$ & $4.3 \%$ & $12.6 \%$ & $20.1 \%$ & $15.2 \%$ & $21.5 \%$ & $11.1 \%$ & $10.4 \%$ & $8.0 \%$ \\
\hline & 58 & 53 & 154 & 245 & 185 & 263 & 136 & 127 & 1221 \\
\hline \multirow[t]{2}{*}{ 91-180 } & $2.0 \%$ & $3.0 \%$ & $7.9 \%$ & $16.0 \%$ & $15.6 \%$ & $26.5 \%$ & $17.7 \%$ & $11.5 \%$ & $5.7 \%$ \\
\hline & 17 & 26 & 68 & 138 & 135 & 229 & 153 & 99 & 865 \\
\hline \multirow[t]{2}{*}{$181-365$} & $6.9 \%$ & $6.9 \%$ & $6.9 \%$ & $6.9 \%$ & $11.7 \%$ & $22.1 \%$ & $20.0 \%$ & $18.6 \%$ & $0.9 \%$ \\
\hline & 10 & 10 & 10 & 10 & 17 & 32 & 29 & 27 & 145 \\
\hline \multirow[t]{2}{*}{$>365$} & $14.3 \%$ & $1.8 \%$ & $10.7 \%$ & $17.9 \%$ & $8.9 \%$ & $8.9 \%$ & $10.7 \%$ & $27.0 \%$ & $0.4 \%$ \\
\hline & 8 & 1 & 6 & 10 & 5 & 5 & 6 & 15 & 56 \\
\hline
\end{tabular}

Bolded cells represent claims where the expected time to RTW was the same at the work-disability duration

$R T W$ return to work

covariates which represent the variables typically collected in administrative databases explained $20.2 \%$ of the variance in work-disability duration (see Table 1 ). In the second step of the analyses, when the expected time to RTW was added to the model, the model then explained $29.8 \%$ of the variance, with the expected time to RTW explaining an additional $9.5 \%$ of the variance in work-disability duration beyond what was explained by the covariates. As hypothesized, the claimants' expected time to RTW was related to work-disability duration, with a greater expected time to RTW being associated with an increase in workdisability duration $(\beta=.346, p<.001)$.

In addition to the main analyses, we conducted a series of sensitivity analyses. As not all claimants were receiving indemnity payments at the time that the RTW expectation estimate was given $(n=2291)$, we conducted the aforementioned analyses limiting our sample to claimants who were receiving indemnity payments for TTD at the time that the RTW expectation estimate was given. In addition, to ensure that the expectation estimate was made reasonably close to the start of TTD, the sample was restricted to those claimants who made the estimate within 2 weeks of starting to receive indemnity payments. Results were consistent in the sensitivity analysis sample with the expected time to RTW being positively related to work-disability duration $(\beta=.314, p<.001)$ and explaining an additional $7.8 \%$ of the variance in work-disability duration beyond the covariates. The results are available upon request.
We also conducted sensitivity analyses limiting our sample to claimants who had finished receiving indemnity payments for TTD within 365 days of RTW expectation data being collected. Findings remained consistent. The correlation between expected time to RTW and TTD duration was $.26(p<.001)$, and the expected time to RTW explained an additional $10.6 \%$ of the variance in work-disability duration after adjusting for the covariates (full model explained variance $=27.4 \%$ ). Finally, we compared the main sample, with claimants who were excluded from the sample due to missing covariate data. Claimants with missing data had significantly $(\mathrm{p}<.001)$ shorter lengths of disability (mean $=60$ days) and expected time to RTW was sooner (mean $=30$ days) than those in the main sample (work-disability durationmean $=79$ days; expected time to RTW-mean $=33$ days). For the claimants who were excluded as a result of missing information, the correlation between work-disability duration and expected time to RTW was slightly higher than for the study sample $(\mathrm{r}=.28$ as compared to $\mathrm{r}=.25){ }^{1}$

\footnotetext{
${ }^{1}$ Of the 3173 claimants excluded for missing information, 170 were missing perceived pain, 186 were missing age, 538 were missing tenure, 344 were missing comorbidity, 410 were missing prior injury, and 1251 were missing industry.
} 


\section{Discussion}

While past research has consistently found that workers' expectations for return to work are predictive of their eventual outcome, understanding of the relationship has been limited by inconsistency in findings, small and restricted study sample sizes and the potential influence of the person collecting the data. Although estimates tended to be more optimistic than was actually the case, the current study's findings support the hypothesis that claimant RTW estimates as recorded by claims managers are significantly related to compensateddisability duration, and that relationship is maintained after controlling for variance that can be explained by other variables contained within workers' compensation data. With being true regardless of whether or not the claimant was in receipt of wage replacement payments at the time of being asked about their RTW expectations. Accuracy was highest for people who expected to RTW within a week. Although accuracy was found to decrease in cases where the estimated time to RTW was greater than 7 days, in more than $40 \%$ of the sample the predicted time to RTW was within 14 days of the end of their TTD payments.

Study findings are consistent with a relationship observed in a recent investigation into RTW following carpal tunnel release [29] where it was found that expected time to RTW explains $18 \%$ of the variance when compared to time to a full RTW. This is despite the current sample's estimated time to RTW being longer than was the case in the earlier study (33.4 days vs. 18.9 days) and our larger sample size $(\mathrm{N}=15,277$ vs. $\mathrm{N}=65)$. Such findings add further support to the idea that injured worker's expectations for RTW can be used in a clinical or insurance setting to gain an understanding of likely future outcome. Further, current study findings also indicated that expected time to RTW, based on our earlier review of the literature [5], allows for the collection of RTW expectation data that is related to disability duration. As such, findings support the suggested measure as being effective for work-disability risk prediction purposes.

When conceptualizing this study we saw the potential for the relationship between RTW expectation and outcome to be influenced by who was questioning the workers about their expectations. More specifically, we saw the potential for workers to give a more "socially desirable" (and thus less accurate) response when they were asked about their RTW timeframes by an insurance representative involved in their case management. While we cannot be sure that this was not the case, we did observe that workers' RTW estimates as recorded by their claims managers were highly predictive of compensated work-disability duration.

Our finding that some of the relationship between RTW expectations and work-disability duration was accounted for by demographic and injury variables is consistent with the idea that RTW expectations represent a self-assessed summary of claimant's individual and contextual biopsychosocial influences $[4,30]$. This finding also adds support to the idea that unpacking the reasoning behind one's expectations, has the potential to assist in the identification of RTW facilitation opportunities, as well as obstacles that may be amenable to intervention with the aim of improving the sickness-absent worker's RTW outcome [31].

In terms of implications for work-disability prevention, our finding that expected RTW was highly predictive of work-disability duration indicates that claims managers can use this information to gain an understanding of likely outcome. It provides a starting point for discussion of what might be done to assist workers to achieve a timely, safe and sustained RTW. If someone expects to RTW in the near future, this suggests that the injured worker has the necessary resources to return without the need for assistance or intervention (making them a "low touch" claim). However, it should be noted that this is not necessarily the case. There may be instances where expectations are unrealistic or forced, in which case there is the potential that the RTW could result in adverse effects [32]. If this is suspected, a low touch approach may not be the appropriate course of action. For persons who provide a far off estimate, this could indicate that help is needed, especially if that person's health condition is relatively minor.

\section{Limitations and Methodological Considerations}

When interpreting study findings the reader should be aware that the end of TTD payments does not necessarily mean RTW. There may be cases where people stopped getting TTD payments but did not RTW. This suggests that the relationship between expectations and disability duration may be stronger than we observed. While the data is consistent with the measure recommended based on our review [5], it is likely that there was inconsistency in how the question was asked. The impact of this potential inconsistency cannot be ascertained. Another limitation is that there are variables of interest (such as workplace relationships, availability of accommodations, work demands and distress) which were not available in the data. Inclusion of these variables would add further insight as to the relationship between RTW expectations and work-disability outcomes.

While previous research on this topic has often been limited by small sample sizes in single industries or focusing on specific injuries, the current findings indicate that the relationship between RTW estimates and disability duration holds true when the sample is large and varied in terms of condition and demographic characteristics. As such, the current results are expected to be generalizable to 
persons with a variety of conditions and socio-economic backgrounds. However, it should be noted that study data were drawn from a single WC insurance provider. As such, it is unclear if findings may be generalized to customers of other WC insurers. This is also true for persons with a work-disabling condition that is not work-related.

The current findings suggest a number of opportunities for future research. From a research perspective it raises questions concerning the malleability of RTW expectations. More specifically, can RTW expectations be changed and, if so, does this result in associated changes in workdisability outcomes? From a practical perspective, questions remain regarding whether having an understanding of RTW expectations helps claims managers in their work with sickness-absent workers' compensation claimants. Does this information help them to identify opportunities for facilitating claimants' RTW and remove barriers that are impeding their progress?

\section{Conclusion}

Study findings add to the body of knowledge indicating a relationship between RTW expectations and RTW outcomes. They demonstrate a relationship that is present when type of condition is varied, and when the sicknessabsent worker is questioned by an insurance representative involved in the worker's claim management. While reported RTW expectations share explanatory power with other variables found in administrative databases, findings indicate that additional insight into likely work-disability duration can be gained through asking the workers when they expect to be back at work.

\section{Compliance with Ethical Standards}

Conflict of interest Authors Amanda Young, Elyssa Besen, Joanna Willetts declares that they have no conflict of interest.

Ethical Approval All procedures performed in studies involving human participants were in accordance with the ethical standards of the institutional and/or national research committee and with the 1964 Helsinki declaration and its later amendments or comparable ethical standards.

Informed Consent The requirement for informed consent was waived by the reviewing IRB (NEIRB-http://www.neirb.com/). The study involved an examination of data drawn from an insurer's administrative database. The risk to study subjects was no more than minimal and the research could not effectively and practicably be carried out without the waiver.

Open Access This article is distributed under the terms of the Creative Commons Attribution 4.0 International License (http://crea tivecommons.org/licenses/by/4.0/), which permits unrestricted use, distribution, and reproduction in any medium, provided you give appropriate credit to the original author(s) and the source, provide a link to the Creative Commons license, and indicate if changes were made.

\section{References}

1. Hunt DG, Zuberbier OA, Kozlowski AJ, Berkowitz J, Schultz IZ, Milner RA, et al. Are components of a comprehensive medical assessment predictive of work disability after an episode of occupational low back trouble? Spine (Phila Pa 1976). 2002;27:2715-9.

2. Schultz IZ, Stowell AW, Feuerstein M, Gatchel RJ. Models of return to work for musculoskeletal disorders. J Occup Rehabil. 2007; 17:327-52.

3. Hallegraeff JM, Krijnen WP, Van Der Schans CP, De Greef MH. Expectations about recovery from acute non-specific low back pain predict absence from usual work due to chronic low back pain: a systematic review. J Physiother. 2012;58:165-72.

4. Iles RA, Davidson M, Taylor NF, O'halloran P. Systematic review of the ability of recovery expectations to predict outcomes in non-chronic non-specific low back pain. J Occup Rehabil. 2009;19:25-40.

5. Young AE, Besen E, Choi Y. The importance, measurement and practical implications of worker's expectations for return to work. Disabil Rehabil. 2015;37:1808-16.

6. Gross DP, Battie MC. Recovery expectations predict recovery in workers with back pain but not other musculoskeletal conditions. J Spinal Disord Tech. 2010;23:451-6.

7. Cole DC, Mondloch MV, Hogg-Johnson S. Listening to injured workers: how recovery expectations predict outcomes-a prospective study. CMAJ. 2002;166:749-54.

8. Turner JA, Franklin G, Fulton-Kehoe D, Sheppard L, Wickizer $\mathrm{TM}, \mathrm{Wu} \mathrm{R}$, et al. Worker recovery expectations and fear-avoidance predict work disability in a population-based workers' compensation back pain sample. Spine (Phila Pa 1976). 2006;31:682-9.

9. Audhoe SS, Hoving JL, Nieuwenhuijsen K, Friperson R, De Jong PR, Sluiter JK, et al. Prognostic factors for the work participation of sick-listed unemployed and temporary agency workers with psychological problems. J Occup Rehabil. 2012;22:437-46.

10. Hogg-Johnson S, Cole DC. Early prognostic factors for duration on temporary total benefits in the first year among workers with compensated occupational soft tissue injuries. Occup Environ Med. 2003;60:244-53.

11. Turner JA, Franklin G, Fulton-Kehoe D, Sheppard L, Wickizer $\mathrm{TM}, \mathrm{Wu}$ R, et al. Early predictors of chronic work disability associated with carpal tunnel syndrome: a longitudinal workers' compensation cohort study. Am J Ind Med. 2007;50:489-500.

12. Nielsen MB, Madsen IE, Bultmann U, Christensen U, Diderichsen F, Rugulies R. Predictors of return to work in employees sicklisted with mental health problems: findings from a longitudinal study. Eur J Public Health. 2011;21:806-11.

13. Jensen OK, Stengaard-Pedersen K, Jensen C, Nielsen CV. Prediction model for unsuccessful return to work after hospital-based intervention in low back pain patients. BMC Musculoskelet Disord. 2013;14:140.

14. Carstens JK, Shaw WS, Boersma K, Reme SE, Pransky G, Linton SJ. When the wind goes out of the sail-declining recovery expectations in the first weeks of back pain. Eur J Pain. 2014;18:269-78.

15. Truchon M, Schmouth ME, Cote D, Fillion L, Rossignol M, Durand MJ. Absenteeism screening questionnaire (ASQ): a new tool for predicting long-term absenteeism among workers with low back pain. J Occup Rehabil. 2012;22:27-50. 
16. Shaw WS, Pransky G, Winters T. The Back Disability Risk Questionnaire for work-related, acute back pain: prediction of unresolved problems at 3-month follow-up. J Occup Environ Med. 2009;51:185-94.

17. Steenstra IA, Koopman FS, Knol DL, Kat E, Bongers PM, De Vet $\mathrm{HC}$, et al. Prognostic factors for duration of sick leave due to lowback pain in Dutch health care professionals. J Occup Rehabil. 2005;15:591-605.

18. Nieuwenhuijsen K, Noordik E, Van Dijk FJ, Van Der Klink JJ. Return to work perceptions and actual return to work in workers with common mental disorders. J Occup Rehabil. 2013;23:290-9.

19. Gross DP, Battie MC. Factors influencing results of functional capacity evaluations in workers' compensation claimants with low back pain. Phys Ther. 2005;85:315-22.

20. Waylett-Rendall J, Niemeyer LO. Exploratory analysis to identify factors impacting return-to-work outcomes in cases of cumulative trauma disorder. J Hand Ther. 2004;17:50-7.

21. Young AE, Wasiak R, Gross DP. Recurrence of work-related low back pain and disability: association between self-report and workers' compensation data. Spine (Phila Pa 1976). 2013;38:2279-86.

22. Oleinick A, Gluck JV, Guire K. Factors affecting first return to work following a compensable occupational back injury. Am J Ind Med. 1996;30:540-55.

23. Berecki-Gisolf J, Clay FJ, Collie A, Mcclure RJ. Predictors of sustained return to work after work-related injury or disease: insights from workers' compensation claims records. J Occup Rehabil. 2012;22:283-91.
24. Besen E, Young AE, Gaines B, Pransky G. Relationship between age, tenure, and disability duration in persons with compensated work-related conditions. J Occup Environ Med. 2016;58:140.

25. Shraim M, Cifuentes M, Willetts JL, Marucci-Wellman HR, Pransky G. Length of disability and medical costs in low back pain: do state workers' compensation policies make a difference? J Occup Environ Med. 2015;57:1275-83.

26. Occupational Safety \& Health Administration. SIC manual. Washington, DC: U.S. Department of Labor; 2014.

27. Ferraz MB, Quaresma MR, Aquino LR, Atra E, Tugwell P, Goldsmith $\mathrm{CH}$. Reliability of pain scales in the assessment of literate and illiterate patients with rheumatoid arthritis. J Rheumatol. 1990;17:1022-4.

28. Bern P. HIREG: Stata module for hierarchical regression. 2005; Stata

29. Cowan J, Makanji H, Mudgal C, Jupiter J, Ring D. Determinants of return to work after carpal tunnel release. J Hand Surg Am. 2012;37:18-27.

30. Iles RA, Taylor NF, Davidson M, O'halloran PD. Patient recovery expectations in non-chronic non-specific low back pain: a qualitative investigation. J Rehabil Med. 2012;44:781-7.

31. Young AE, Choi Y, Besen E. An exploration of the factors considered when forming expectations for returning to work following sickness absence due to a musculoskeletal condition. PLoS ONE. 2015;10:e0143330.

32. Pransky G, Benjamin K, Hill-Fotouhi C, Himmelstein J, Fletcher $\mathrm{KE}$, Katz JN, et al. Outcomes in work-related upper extremity and low back injuries: results of a retrospective study. Am J Ind Med. 2000;37:400-9. 